\title{
Misclassification and characterization of exposure to humidifier disinfectants using a questionnaire
}

Hyeonsu Ryu', Yoon-Hyeong Choi ${ }^{2}$ Eunchae Kim', Jinhyeon Park', Seula Lee², Jeonggyo Yoon², Eun-Kyung Jo², Youngtae Choe ${ }^{1}$, Jung $\mathrm{Heo}^{1}$ and Wonho Yang ${ }^{1 *}$ (D)

\begin{abstract}
Background: Lung disease caused by exposure to chemical substances such as polyhexamethylene guanidine (PHMG) used in humidifier disinfectants (HDs) has been identified in Korea. Several researchers reported that exposure classification using a questionnaire might not correlate with the clinical severity classes determined through clinical diagnosis. It was asserted that the lack of correlation was due to misclassification in the exposure assessment due to recall bias. We identified the cause of uncertainty to recognize the limitations of differences between exposure assessment and clinical outcomes assumed to be true value. Therefore, it was intended to check the availability of survey using questionnaires and required to reduce misclassification error/bias in exposure assessment.

Methods: HDs exposure assessment was conducted as a face-to-face interview, using a questionnaire. A total of 5245 applicants participated in the exposure assessment survey. The questionnaire included information on sociodemographic and exposure characteristics such as the period, frequency, and daily usage amount of HDs. Based on clinical diagnosis, a $4 \times 4$ cross-tabulation of exposure and clinical classification was constructed. When the values of the exposure rating minus the clinical class were $\geq 2$ and $\leq-2$, we assigned the cases to the overestimation and underestimation groups, respectively.
\end{abstract}

Results: The sex ratio was similar in the overestimation and underestimation groups. In terms of age, in the overestimation group, 90 subjects (24.7\%) were under the age of 10, followed by 52 subjects (14.2\%) in their 50s. In the underestimation group, 195 subjects (56.7\%) were under the age of 10, followed by 80 subjects (23.3\%) in their 30s. The overestimation group may have already recovered and responded excessively due to psychological anxiety or to receive compensation. However, relatively high mortality rates and surrogate responses observed among those under 10 years of age may have resulted in inaccurate exposure in the underestimation group.

Conclusions: HDs exposure assessment using a questionnaire might not correlate with adverse health effects due to recall bias and various other causes such as recovery of injury and psychological anxiety. This study revealed exposure misclassification and characteristics affected by HDs and proposed a questionnaire-based exposure assessment methodology to overcome the limitations of past exposure assessment.

Keywords: Humidifier disinfectants, Past exposure assessment, Misclassification, Questionnaire

\footnotetext{
* Correspondence: whyang@cu.ac.kr

'Department of Occupational Health, Daegu Catholic University, Hayang-eup, Gyeongsan-si, Gyeongbuk 38430, South Korea

Full list of author information is available at the end of the article
}

C C The Author(s). 2021 Open Access This article is licensed under a Creative Commons Attribution 4.0 International License, which permits use, sharing, adaptation, distribution and reproduction in any medium or format, as long as you give appropriate credit to the original author(s) and the source, provide a link to the Creative Commons licence, and indicate if changes were made. The images or other third party material in this article are included in the article's Creative Commons. licence, unless indicated otherwise in a credit line to the material. If material is not included in the article's Creative Commons licence and your intended use is not permitted by statutory regulation or exceeds the permitted use, you will need to obtain permission directly from the copyright holder. To view a copy of this licence, visit http://creativecommons.org/licenses/by/4.0/. The Creative Commons Public Domain Dedication waiver (http://creativecommons.org/publicdomain/zero/1.0/) applies to the data made available in this article, unless otherwise stated in a credit line to the data. 


\section{Background}

A humidifier may be one of the essential devices required in the dry winter season. Humidifiers emit water vapor or steam to increase humidity. In Korea, most of the homes and offices use humidifiers to maintain indoor humidity and prevent respiratory infections and infections caused by viruses [1]. However, when the water tank of the humidifier is not kept clean, growth of germs, molds, and/or algae can be observed. This results in contaminated vapor, which can enter the lungs directly and cause risk to human health [2].

To prevent the propagation of germs in a humidifier, humidifier disinfectants (HDs) were designed as a chemical additive in Korea. According to the Korea Centers for Disease Control and Prevention (KCDC), approximately 20 different products have been sold since 1994 . However, these were completely banned in 2011 when their risk was identified [3]. The major ingredients in the HDs were polyhexamethylene guanidine (PHMG), oligo (2-)ethoxyethoxyethyl guanidine chloride (PGH), chloromethylisothiazolinone (CMIT), and methylisothiazolinone (MIT) [4]. PHMG was the most commonly used ingredient in HDs. These products were manufactured by multinational companies, including Oxy Ssackssak New Gaseupgi Dangbun of Reckitt Benckiser (U.K.), Homeplus Gaseupgi Mate of Tesco (U.K.), Nwith For Humidifier of Medentech (Ireland), Homekeeper Gaseupgi Hanbune Ssak of Henkel (Germany), Sandokkaebi Gaseupgi Punisher of Daiso (Japan), and Vegetable Home Gaseupgi Cleanup of Costco (U.S.) [5].

Epidemiological research and toxicological experiments have shown the effects of exposure to HDs, such as lung disease, asthma, and interstitial lung diseases [6, 7]. By February 2020, a total of 6735 people had enrolled for compensation due to the damage caused by HDs, and the compensation request can be applied through a website [8]. Among them, 1528 died and 487 have had lung disease thus far.

Although HDs have been produced and used in other countries such as the United States of America, Germany, and Japan, they are made up of alcohol or natural ingredients such as eucalyptus; furthermore, they were not widely used. The U.S. Environmental Protection Agency (EPA) recommends that humidifiers should be rinsed with tap water several times after cleaning with a humidifier cleaner or HD to prevent chemicals from spreading through the air [9].

Exposure assessment by personal exposure or biomonitoring was not possible because the adverse effects of HD exposure could not be determined in 2011. Therefore, past exposure assessment could only be estimated using a questionnaire and an indoor air quality model [10]. For clinical classification, HD-related lung damage has been categorized as class 1 (unlikely), class 2 (possible), class 3 (probable), class 4 (definite), and indeterminate through the deliberation of a committee composed of clinicians and public health doctors in an initiative of the Ministry of Environment, Korea [11]. Clinical evidence of HDs exposure included (1) acute or subacute development of cough, dyspnea, or breathlessness, (2) physical signs of spontaneous air leakage, including subcutaneous or mediastinal emphysema, and (3) chest radiographic features of terminal bronchiolar damage [12]. The four classes in the clinical classification were identified by HD-specific singularity, while it might be argued that exposure rating based on the questionnaire may be misclassified due to erroneous statements, leading to recall bias. Therefore, a new methodology was required to reduce misclassification in exposure assessment. This study aimed to propose a methodology to effectively classify the levels of exposure to HDs using a questionnaire.

\section{Methods \\ HD exposure survey}

HD exposure assessment survey was conducted face-toface with by public health experts who qualified by completing regular education from the Korean Society of Environmental Health (KSEH). A total of 25 interviewers from $\mathrm{KSEH}$ including authors participated in this survey. Furthermore, the survey results were and cross-checked to enhance the reliability of the questionnaire. They visited the homes of each subject who had applied for compensation and conducted personal interviews and home investigation to complete the questionnaire or checklist related to HD usage. In cases where the person was deceased or unavailable for interview because they were too young under the age of 13, the investigation was conducted with one of the family members who lived with them, such as their parents [13]. At this time, the consent form was obtained through a document with handwritten signature. The questionnaire included information of sociodemographic and exposure characteristics such as the product names of the HD used, ingredients, usage period, frequency of use, and daily usage amount of humidifier disinfectant. The questionnaire used was illustrated in the supplementary material. Additionally, information on the room volume, humidifier location, spraying direction, and objective evidence such as photographs of products and receipt as a proof was collected.

A total of 5245 applicants (4028 survivors and 1217 deaths) completed the exposure survey by the end of 2018. Among them, 3456 used PHMG-containing products. This study was approved by the Institutional Review Board of Daegu Catholic University (IRB No. CUIRB-2016-011). 


\section{Level of exposure to HDs}

To assess exposure to HDs in indoor environments, exposure levels, which are a function of indoor concentration and exposure time, were calculated. The ventilation rate for the room used was not considered. The concentration of PHMG dissolved in HD product was used according to the results of the Ministry of Food and Drug Safety [3]. The indoor air concentration of PHMG, cumulative exposure time, and exposure level were calculated using the following equations:

- Indoor air concentration $\left(\mu \mathrm{g} / \mathrm{m}^{3}\right)=$ average daily use $(\mathrm{mL})$ x PHMG concentration in products $(\mu \mathrm{g} / \mathrm{mL}) /$ volume of used space $\left(\mathrm{m}^{3}\right)$.

- Cumulative exposure time $(\mathrm{hr})=$ total years $\mathrm{x}$ months per year $\mathrm{x}$ weeks per month $\mathrm{x}$ days per week $\mathrm{x}$ hours per day.

- Exposure level $\left(\mu \mathrm{g} / \mathrm{m}^{3} \cdot \mathrm{hr}\right)=$ indoor concentration $\left(\mu \mathrm{g} / \mathrm{m}^{3}\right) \times$ cumulative exposure time $(\mathrm{hr})$.

Many studies have classified exposure into 4 classes according to the clinical diagnosis criteria for lung diseases $[14,15]$. Accordingly, the clinical class and exposure rating were classified into four stages. Clinical classification, which was performed by a committee made up of respiratory pulmonologists, radiologists, pathologists, and epidemiologists without information on the type of HDs, divided HD-related lung damage as class 1 (unlikely), class 2 (possible), class 3 (probable), and class 4 (definite) [16].

The calculated indoor air concentration, cumulative exposure time, and exposure level were arranged in the order of maximum to minimum and then classified by percentage based on clinical diagnosis class that was assumed as the true value [17]. The exposure classification was defined as rating 1 (extreme low exposure), rating 2 (low exposure), rating 3 (medium exposure), and rating 4 (high exposure).

When the value of the exposure rating minus the clinical class was 0 or 1 , we assumed these to be the true value. However, when the value was $\geq 2$ or $\leq-2$, we assigned the participants to the overestimation group (high exposure but mild symptoms) or the underestimation group (low exposure but severe symptoms), respectively [18]. The exposure-response relationship was derived from the relationship between exposure to HDs and development of lung disease, excluding the overestimation and underestimation groups $[19,20]$.

\section{Statistical analysis}

Statistical analyses were performed using SPSS version 19 (IBM Company, USA). A chi-square test was used to analyze the relationship between clinical class and exposure rating. The significance level was set as $p$-value of $<0.05$ in all analyses. Using Origin 8.0 (Origin Lab. Co., Northampton, MA, USA), the relationship between clinical class and exposure level was derived by the curve fitting technique.

\section{Results}

Social and demographic characteristics according to clinical classification are shown in Table 1. The total number of subjects in classes 1 and 2 by clinical classification was 4632. The demographic characteristics according to the clinical class groups were significantly different $(p<0.01)$. The number of male and female subjects was similar at 2675 and 2547, respectively, and the number of subjects with unknown sex was relatively very low. The number of survived subjects increased from class 1 to class 4 . In terms of age at damage, the number of applicants under the age of 10 was 1536, and 452 subjects had unknown age. There were 339 pregnant women and 439 fetuses among those exposed to HDs.

The product names of HDs used according to clinical class are shown in Table 2. The HD products and chemical type according to the clinical classification showed significant differences $(p<0.01)$. Most of the subjects answered that they used the Oxy Ssakssak New Gaseupgi Dangbun, followed by Cefu Gaseupgi Salgyunje in clinical classes 1 and 2, and by Ekyung Gaseupgi Mate in clinical classes 3 and 4. However, 252 subjects did not remember the name of the HD products used in clinical classes 3 and 4 . The main ingredient of the HDs used was PHMG.

A cross-tabulation of the clinical class and exposure rating is shown in Table 3. There was a significant difference between the exposure ratings and clinical classes $(p<0.05)$. Focusing on the exposure level, 365 subjects with clinical class 1 , exposure rating 3 and 4 , and clinical class 2 , exposure rating 4 , were assumed as the overestimation group. However, 344 subjects with clinical classes 3 and 4, exposure rating 1, and clinical class 4, exposure rating 2 , were assumed as the underestimation group.

The demographic and exposure characteristics of these groups are shown in Table 4. The sex ratio was similar in the overestimation and underestimation groups. In the overestimation group, 90 subjects (24.7\%) were under the age of 10, followed by 52 subjects (14.2\%) in their 50s. In the underestimation group, 195 subjects $(56.7 \%)$ were under the age of 10 , followed by 80 subjects $(23.3 \%)$ in their 30s. There were no current smokers in the underestimation group. The amount sprayed, the distance between the humidifier and the respiratory organ of the subject such as the nose and mouth, and spraying direction were crucial factors affecting exposure. The overestimation group was characterized by more vigorous spray amounts, closer distance 
Table 1 Social and demographic characteristics according to clinical classification

\begin{tabular}{|c|c|c|c|c|c|c|c|c|c|c|c|c|c|}
\hline \multirow[t]{2}{*}{ Characteristics } & \multicolumn{2}{|c|}{ Class 1} & \multicolumn{2}{|c|}{ Class 2} & \multicolumn{2}{|c|}{ Class 3} & \multicolumn{2}{|c|}{ Class 4} & \multicolumn{2}{|c|}{ Indetermination } & \multicolumn{2}{|l|}{ Total } & \multirow[t]{2}{*}{$p$-value } \\
\hline & $N$ & $(\%)$ & $\mathrm{N}$ & $(\%)$ & $\mathrm{N}$ & $(\%)$ & $\mathrm{N}$ & $(\%)$ & $\mathrm{N}$ & (\%) & $\mathrm{N}$ & (\%) & \\
\hline Total & 4351 & 83.0 & 281 & 5.4 & 204 & 3.9 & 264 & 5.0 & 145 & 2.8 & 5245 & 100.0 & \\
\hline Sex & & & & & & & & & & & & & $<0.01$ \\
\hline Male & 2285 & 85.4 & 113 & 4.2 & 89 & 3.3 & 146 & 5.5 & 70 & 2.6 & 2675 & 100.0 & \\
\hline Female & 2063 & 81.0 & 168 & 6.6 & 115 & 4.5 & 118 & 4.6 & 55 & 2.2 & 2547 & 100.0 & \\
\hline Unknown & 3 & 13.0 & 0 & 0.0 & 0 & 0.0 & 0 & 0.0 & 20 & 87.0 & 23 & 100.0 & \\
\hline Survival status & & & & & & & & & & & & & $<0.01$ \\
\hline Survival & 3479 & 86.4 & 215 & 5.3 & 133 & 3.3 & 72 & 1.8 & 72 & 1.8 & 4027 & 100.0 & \\
\hline Death & 872 & 71.6 & 66 & 5.4 & 71 & 5.8 & 73 & 6.0 & 73 & 6.0 & 1218 & 100.0 & \\
\hline Age at damage (years) & & & & & & & & & & & & & $<0.01$ \\
\hline$<10$ & 1088 & 70.8 & 142 & 9.2 & 106 & 6.9 & 145 & 9.4 & 55 & 3.6 & 1536 & 100.0 & \\
\hline $10 \mathrm{~s}$ & 117 & 91.4 & 3 & 2.3 & 1 & 0.8 & 3 & 2.3 & 4 & 3.1 & 128 & 100.0 & \\
\hline $20 \mathrm{~s}$ & 299 & 89.0 & 10 & 3.0 & 8 & 2.4 & 12 & 3.6 & 7 & 2.1 & 336 & 100.0 & \\
\hline $30 \mathrm{~s}$ & 755 & 82.3 & 41 & 4.5 & 33 & 3.6 & 72 & 7.9 & 16 & 1.7 & 917 & 100.0 & \\
\hline $40 \mathrm{~s}$ & 467 & 91.2 & 20 & 3.9 & 12 & 2.3 & 6 & 1.2 & 7 & 1.4 & 512 & 100.0 & \\
\hline $50 \mathrm{~s}$ & 501 & 91.3 & 18 & 3.3 & 14 & 2.6 & 8 & 1.5 & 8 & 1.5 & 549 & 100.0 & \\
\hline $60 \mathrm{~s}$ & 459 & 91.8 & 18 & 3.6 & 12 & 2.4 & 4 & 0.8 & 7 & 1.4 & 500 & 100.0 & \\
\hline $70 \mathrm{~s}$ & 240 & 92.7 & 12 & 4.6 & 3 & 1.2 & 1 & 0.4 & 3 & 1.2 & 259 & 100.0 & \\
\hline$\geq 80$ & 53 & 94.6 & 1 & 1.8 & 0 & 0.0 & 0 & 0.0 & 2 & 3.6 & 56 & 100.0 & \\
\hline Unknown & 372 & 82.3 & 16 & 3.5 & 15 & 3.3 & 13 & 2.9 & 36 & 8.0 & 452 & 100.0 & \\
\hline Susceptible group & & & & & & & & & & & & & $<0.01$ \\
\hline Pregnant women & 261 & 77.0 & 10 & 3.0 & 18 & 5.3 & 44 & 13.0 & 6 & 1.7 & 339 & 100.0 & \\
\hline Fetus & 311 & 70.8 & 42 & 9.6 & 30 & 6.8 & 17 & 3.9 & 39 & 8.9 & 439 & 100.0 & \\
\hline Others & 3779 & 84.6 & 229 & 5.1 & 156 & 3.5 & 203 & 4.6 & 100 & 2.2 & 4467 & 100.0 & \\
\hline
\end{tabular}

to the humidifier, and direct spraying to the breathing zone than the underestimation group.

A comparison of the HD usage characteristics between the overestimation and underestimation groups is shown in Table 5. The overestimation group showed much higher usage characteristics than the underestimation group. The overestimation group showed a significant difference with other groups in the number of months used, one-time use, and daily use time.

Results of regression analysis and curve fitting of the indoor concentration, cumulative exposure time, and exposure level with the clinical classes are shown in Figs. 1, 2 , and 3, respectively, after the overestimation and underestimation groups were removed. The regression formula between the exposure level $(\mathrm{X})$ and clinical class (Y) was $\mathrm{Y}=0.92+3.24 \mathrm{E}-19 * \operatorname{Exp}((\mathrm{X}-20.45) / 0.88)$, and the coefficient of determination $\left(\mathrm{R}^{2}\right)$ value was $0.58(p<$ 0.01). As a result of comparing the relationship between exposure ratings and clinical classes, the breakpoint of exposure level between clinical classes 1 (unlikely) and 2 (possible) was $14.73 \mu \mathrm{g} / \mathrm{m}^{3} \cdot \mathrm{hr}$., which was considered to exert adverse health effects, especially lung disease. The exposure level for government compensation of clinical classes 3 and 4 was about $17.57 \mu \mathrm{g} / \mathrm{m}^{3} \cdot \mathrm{hr}$.

\section{Discussion}

Exposure classification using a questionnaire might not correlate with the clinical severity classes determined through clinical diagnosis due to misclassification of exposure assessment due to erroneous statements based on recall bias [21].. This study identified the sociodemographic and exposure characteristics of subjects affected by HDs focusing on PHMG and suggested a questionnaire-based exposure assessment methodology to overcome the limitations of past exposure assessment. By identifying the limitations of the questionnaire, the exposure assessment to the humidifier disinfectant using the questionnaire can be enhanced.

Exposure assessment using a questionnaire might result in recall bias. Certain groups of subjects, such as children and the elderly, are more susceptible to exposure than the general population, and they may easily have health effects even at low exposure to hazardous agents [22]. Potential causes of increased susceptibility 
Table 2 Product names of humidifier disinfectants according to clinical classification

\begin{tabular}{|c|c|c|c|c|c|c|c|c|c|}
\hline & \multicolumn{2}{|c|}{ Class 1, 2} & \multicolumn{2}{|c|}{ Class 3, 4} & \multicolumn{2}{|c|}{ Indetermination } & \multicolumn{2}{|l|}{ Total } & \multirow[t]{2}{*}{$p$-value } \\
\hline & $\mathrm{N}$ & $(\%)$ & $\mathrm{N}$ & $(\%)$ & $\mathrm{N}$ & $(\%)$ & $\mathbf{N}$ & (\%) & \\
\hline Products & 4632 & 88.3 & 468 & 8.9 & 145 & 2.8 & 5245 & 100.0 & \\
\hline Oxy Ssakssak New Gaseupgi Dangbun & 3419 & 88.2 & 356 & 9.2 & 101 & 2.6 & 3876 & 100.0 & $<0.01$ \\
\hline Ekyung Gaseupgi Mate & 458 & 92.3 & 24 & 4.8 & 14 & 2.8 & 496 & 100.0 & \\
\hline E-Mart Gaseupgi Salgyunje & 112 & 91.8 & 9 & 7.4 & 1 & 0.8 & 122 & 100.0 & \\
\hline WiseLect Gaseupgi Salgyunje & 77 & 74.0 & 26 & 25.0 & 1 & 1.0 & 104 & 100.0 & \\
\hline Homeplus Gaseupgi Chungjungje & 105 & 89.0 & 12 & 10.2 & 1 & 0.8 & 118 & 100.0 & \\
\hline Vegetable Home Gaseupgi Cleanup & 44 & 97.8 & 1 & 2.2 & 0 & 0.0 & 45 & 100.0 & \\
\hline Cefu Gaseupgi Salgyunje & 49 & 60.5 & 30 & 37.0 & 2 & 2.5 & 81 & 100.0 & \\
\hline Others & 116 & 87.9 & 3 & 2.3 & 13 & 9.8 & 132 & 100.0 & \\
\hline Unknown & 252 & 93.0 & 7 & 2.6 & 12 & 4.4 & 271 & 100.0 & \\
\hline \multicolumn{10}{|l|}{ Chemical type } \\
\hline PHMG & 3642 & 88.0 & 395 & 9.5 & 103 & 2.5 & 4140 & 100.0 & $<0.01$ \\
\hline CMIT/MIT & 611 & 91.6 & 35 & 5.2 & 21 & 3.1 & 667 & 100.0 & \\
\hline PGH & 50 & 60.2 & 31 & 37.3 & 2 & 2.4 & 83 & 100.0 & \\
\hline Others & 73 & 91.3 & 0 & 0.0 & 7 & 8.8 & 80 & 100.0 & \\
\hline Unknown & 256 & 93.1 & 7 & 2.5 & 12 & 4.4 & 275 & 100.0 & \\
\hline
\end{tabular}

include genetic factors, age, sex, pre-existing disease, inadequate nutrition, and stress [23-25]. Pregnancy may also be one of the susceptible factors [26].

Although the total number of men was higher than that of women, relatively more women were in clinical classes 1 and 2, for which government compensation was recognized. The incidence of disease by exposure to hazardous pollutants is generally higher in women than in men [27, 28]. The survival rate was relatively low, given that there were 1218 deaths and 4027 survivors.
However, 261 survivors and 207 deaths accounted for a high rate of adverse health effects due to HDs in clinical classes 1 and 2.

Exposure assessment of HDs was carried out using a questionnaire. Although the face-to-face interview survey consumed a great amount of effort and time, exposure classification using a questionnaire might not correlate with the clinical severity classes determined through clinical diagnosis. There was some uncertainty regarding the overestimation and underestimation

Table 3 Cross-tabulation between clinical classes and exposure ratings

\begin{tabular}{|c|c|c|c|c|c|c|c|}
\hline & & \multicolumn{4}{|c|}{ Clinical class } & \multirow[t]{2}{*}{ Total } & \multirow[t]{2}{*}{$p$-value } \\
\hline & & Class 1 & Class 2 & Class 3 & Class 4 & & \\
\hline \multirow[t]{4}{*}{ Indoor concentration } & Rating 1 & 2406 & 172 & 134 & 157 & 2869 & 0.04 \\
\hline & Rating 2 & 165 & 12 & 10 & 19 & 206 & \\
\hline & Rating 3 & 137 & 16 & 7 & 13 & 173 & \\
\hline & Rating 4 & 169 & 9 & 8 & 22 & 208 & \\
\hline \multirow[t]{4}{*}{ Cumulative exposure time } & Rating 1 & 2339 & 186 & 144 & 200 & 2869 & $<0.01$ \\
\hline & Rating 2 & 188 & 7 & 6 & 5 & 206 & \\
\hline & Rating 3 & 159 & 6 & 5 & 3 & 173 & \\
\hline & Rating 4 & 191 & 10 & 4 & 3 & 208 & \\
\hline \multirow[t]{5}{*}{ Exposure level } & Rating 1 & 2357 & 181 & 143 & 188 & 2869 & $<0.01$ \\
\hline & Rating 2 & 166 & 15 & 12 & 13 & 206 & \\
\hline & Rating 3 & 162 & 2 & 0 & 9 & 173 & \\
\hline & Rating 4 & 192 & 11 & 4 & 1 & 208 & \\
\hline & Total & 2877 & 209 & 159 & 211 & 3456 & \\
\hline
\end{tabular}


Table 4 Comparison of demographic and exposure characteristics in the underestimation and overestimation groups

\begin{tabular}{|c|c|c|c|c|c|c|c|}
\hline \multirow[t]{2}{*}{ Variables } & & \multicolumn{2}{|c|}{$\begin{array}{l}\text { Overestimation } \\
\text { group }\end{array}$} & \multicolumn{2}{|c|}{$\begin{array}{l}\text { Underestimation } \\
\text { group }\end{array}$} & \multicolumn{2}{|c|}{$\begin{array}{l}\text { Others (true-assumed } \\
\text { group) }\end{array}$} \\
\hline & & $\mathbf{N}$ & $\%$ & $\mathrm{~N}$ & $\%$ & $\mathrm{~N}$ & $\%$ \\
\hline \multirow[t]{3}{*}{ Sex } & Male & 193 & 52.9 & 150 & 43.6 & 1416 & 51.5 \\
\hline & Female & 172 & 47.1 & 194 & 56.4 & 1329 & 48.4 \\
\hline & Unknown & 0 & 0.0 & 0 & 0.0 & 2 & 0.1 \\
\hline \multirow[t]{9}{*}{ Age at damage (years) } & $<10$ & 90 & 24.7 & 195 & 56.7 & 790 & 28.8 \\
\hline & $10 \mathrm{~s}$ & 12 & 3.3 & 3 & 0.9 & 71 & 2.6 \\
\hline & $20 \mathrm{~s}$ & 22 & 6.0 & 16 & 4.7 & 202 & 7.4 \\
\hline & $30 \mathrm{~s}$ & 41 & 11.2 & 80 & 23.3 & 535 & 19.5 \\
\hline & $40 \mathrm{~s}$ & 45 & 12.3 & 13 & 3.8 & 272 & 9.9 \\
\hline & $50 \mathrm{~s}$ & 52 & 14.2 & 12 & 3.5 & 290 & 10.6 \\
\hline & $60 \mathrm{~s}$ & 43 & 11.8 & 9 & 2.6 & 263 & 9.6 \\
\hline & $\geq 70$ & 33 & 9.0 & 3 & 0.9 & 148 & 5.4 \\
\hline & Unknown & 27 & 7.4 & 13 & 3.8 & 176 & 6.4 \\
\hline \multirow[t]{4}{*}{ Smoking status } & Current smoker & 17 & 4.7 & 0 & 0 & 109 & 4.0 \\
\hline & Former smoker & 88 & 24.1 & 17 & 4.9 & 511 & 18.6 \\
\hline & Never smoker & 260 & 71.2 & 322 & 93.6 & 2110 & 76.8 \\
\hline & Unknown & 0 & 0 & 5 & 1.5 & 17 & 0.6 \\
\hline \multirow[t]{2}{*}{ Survival status } & Survival & 276 & 75.6 & 208 & 60.5 & 2300 & 83.7 \\
\hline & Death & 89 & 24.4 & 136 & 39.5 & 447 & 16.3 \\
\hline \multirow[t]{3}{*}{ Job status } & Employed & 147 & 40.3 & 74 & 21.5 & 1165 & 42.4 \\
\hline & Unemployed & 216 & 59.2 & 193 & 56.1 & 1432 & 52.1 \\
\hline & Unknown & 2 & 0.5 & 77 & 22.4 & 150 & 5.5 \\
\hline \multirow[t]{3}{*}{ Ventilation status } & Ventilated & 214 & 58.6 & 245 & 71.2 & 1192 & 61.2 \\
\hline & Non-ventilated & 147 & 40.3 & 90 & 26.2 & 590 & 30.3 \\
\hline & Unknown & 4 & 1.1 & 9 & 2.6 & 165 & 6.0 \\
\hline \multirow[t]{5}{*}{ Sprayed amount } & Least & 2 & 0.5 & 18 & 5.2 & 35 & 1.3 \\
\hline & Slightly & 10 & 2.7 & 38 & 11.1 & 203 & 7.4 \\
\hline & Moderate & 169 & 46.3 & 180 & 52.3 & 1461 & 53.2 \\
\hline & Strong & 173 & 47.4 & 99 & 28.8 & 994 & 36.2 \\
\hline & Unknown & 11 & 3.0 & 9 & 2.6 & 54 & 2.0 \\
\hline \multirow[t]{5}{*}{ Disance between the humidifier and the face of subject } & $<0.5 \mathrm{~m}$ & 131 & 35.9 & 51 & 14.8 & 752 & 27.4 \\
\hline & $0.5 m \leq-<1 m$ & 156 & 42.7 & 116 & 33.7 & 1052 & 38.3 \\
\hline & $1 m \leq-<2 m$ & 62 & 17.0 & 120 & 34.9 & 728 & 26.5 \\
\hline & $\geq 2 \mathrm{~m}$ & 14 & 3.8 & 56 & 16.3 & 207 & 7.5 \\
\hline & Unknown & 2 & 0.5 & 1 & 0.3 & 8 & 0.3 \\
\hline \multirow[t]{3}{*}{ Spraying direction } & To breathing zone & 278 & 76.2 & 173 & 50.3 & 1841 & 67.0 \\
\hline & To others & 82 & 22.4 & 151 & 43.9 & 857 & 31.2 \\
\hline & Unknown & 5 & 1.4 & 20 & 5.8 & 49 & 1.8 \\
\hline
\end{tabular}

exposure groups compared to clinical classes based on the clinical diagnosis. This may have been due to misclassification in the exposure assessment due to erroneous statements based on recall bias.
Relatively, there were more males in the overestimation group and more females in the underestimation group. The mortality rate was higher in the underestimation groups. This could indicate that the 
Table 5 Comparison of factors affecting exposure levels in the underestimation and overestimation groups

\begin{tabular}{|c|c|c|c|c|c|c|}
\hline \multirow[t]{2}{*}{ Variables } & \multicolumn{2}{|c|}{ Overestimation group } & \multicolumn{2}{|c|}{ Underestimation group } & \multicolumn{2}{|c|}{ Others (true-assumed group) } \\
\hline & Mean & S.D. & Mean & S.D. & Mean & S.D. \\
\hline Period (month) & 69.8 & 40.1 & 15.4 & 14.3 & 25.0 & 21.6 \\
\hline Amount of use (mL) & 27.5 & 32.2 & 14.8 & 8.7 & 14.6 & 12.2 \\
\hline Daily usage time (hr) & 18.4 & 5.8 & 12.8 & 5.1 & 12.2 & 5.7 \\
\hline Usage time for sleeping (hr) & 9.0 & 3.3 & 7.7 & 1.7 & 7.8 & 3.2 \\
\hline Indoor concentration $\left(\mu \mathrm{g} / \mathrm{m}^{3}\right)$ & 1914.1 & 2401.2 & 771.6 & 665.5 & 647.0 & 690.7 \\
\hline Cumulative exposure time (hr) & $34,548.6$ & $22,997.0$ & 5191.7 & 5667.3 & 7702.4 & 8185.3 \\
\hline Exposure level $\left(\mu \mathrm{g} / \mathrm{m}^{3} \cdot \mathrm{hr}\right)$ & $49,483,924$ & $74,191,015$ & $3,552,275$ & $3,657,695$ & $4,473,117$ & $5,260,741$ \\
\hline
\end{tabular}

* S.D. standard deviation

overestimation groups may have already recovered with no ongoing symptoms [29]. The psychological anxiety and shock from the HD disaster could also have caused overreaction [30-32]. However, the underestimation group had shorter HD usage (months) in terms of period and amount. Relatively high death rates and surrogate responses for children under 10 years old may have resulted in inaccurate exposure.

In the previous study conducted by Park et al., the HD exposure classification was conducted by setting eight influencing factors and assessing them as "yes" or "no" depending on the clinical results [33]. However, this method may further increase exposure bias because it contains subjective qualitative evaluation. Therefore, the exposure level was calculated using the indoor PHMG concentration by modeling and exposure time in this study because there is no the gold standard for observational data to verify self-reported data [34]. Apart from exposure assessment, the clinical classes based on the clinical diagnosis assuming these values are true were classified because HD-specificity in the X-ray image might be regarded as actual exposure [35].

The point of departure (POD) of the no-observedadverse-effect level (NOAEL) value for PHMG was found to be lower than $0.15 \mathrm{mg} / \mathrm{m}^{3}$ in a 28 -day inhalation toxicity test using rats [36]. The inhalation RfC value of PHMG was calculated to be $0.143 \mu \mathrm{g} / \mathrm{m}^{3}(150 /$ 1048.95) based on uncertainty correction (300; interspecies 3 , intraspecies 10 , duration 10 , severity 1 , modifying factor 1) and assessment factors (0.286, adjustment 0.179 , equivalent 1.6) [37]. In this study, the exposure concentration calculated using the relationship between

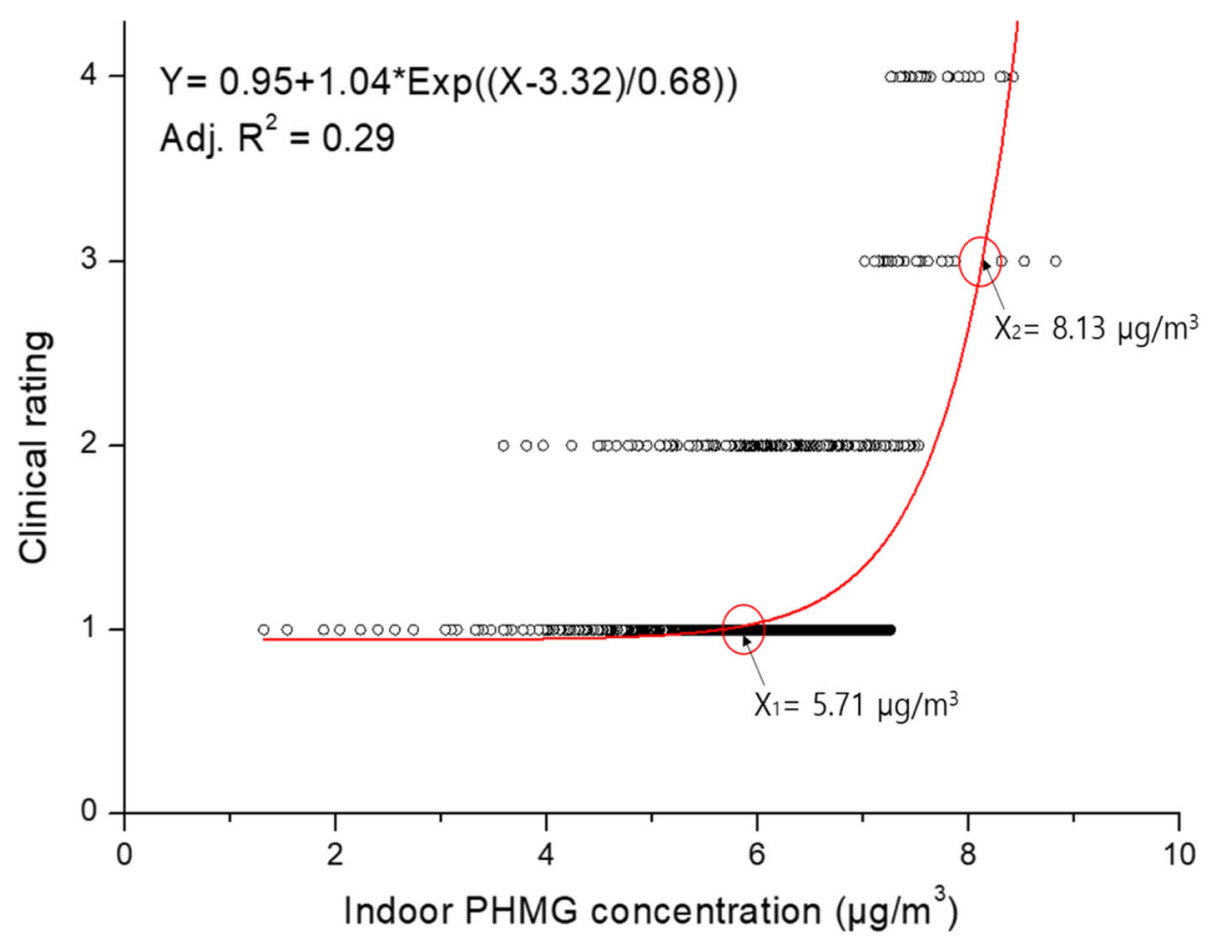

Fig. 1 Regression analysis between indoor polyhexamethylene guanidine (PHMG) concentrations and clinical class 


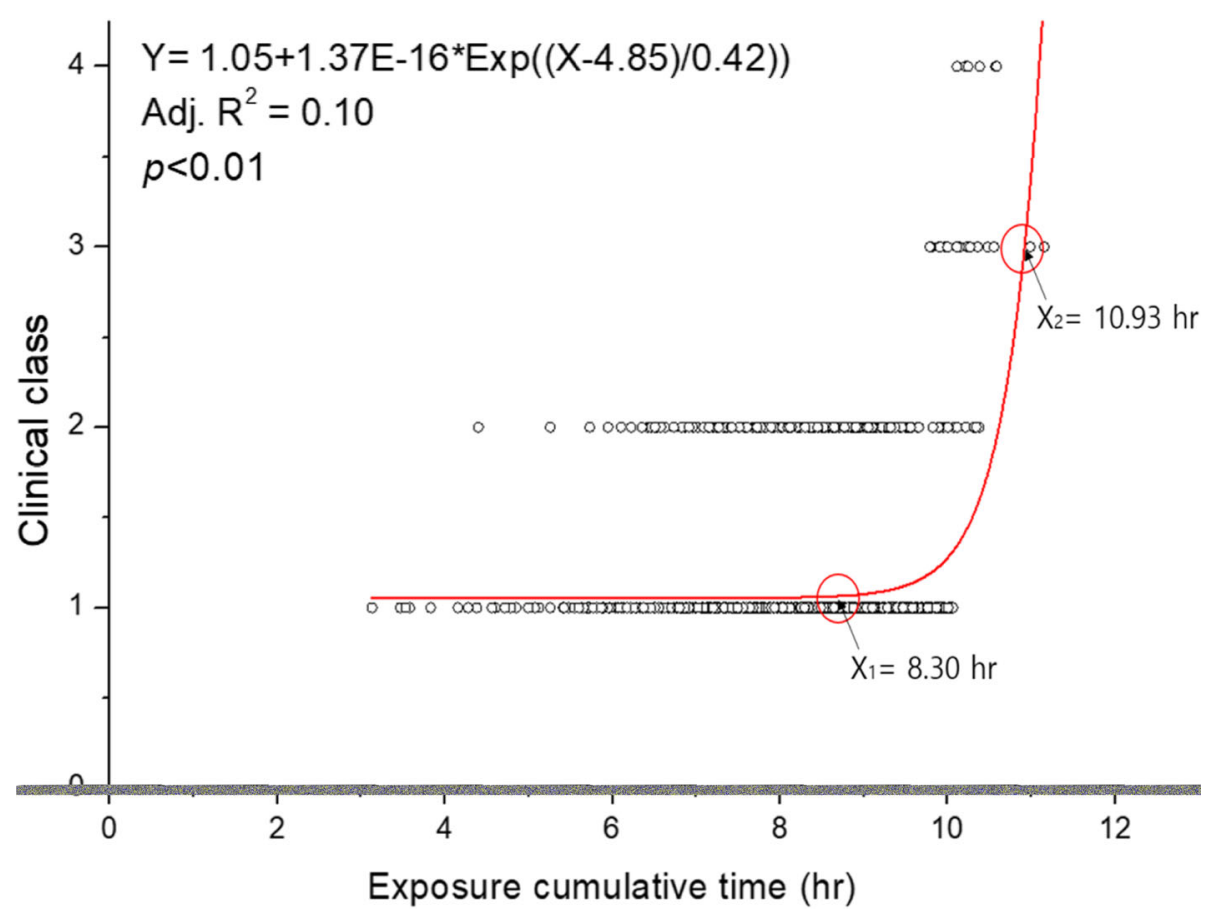

Fig. 2 Regression analysis between exposure cumulative time and clinical class

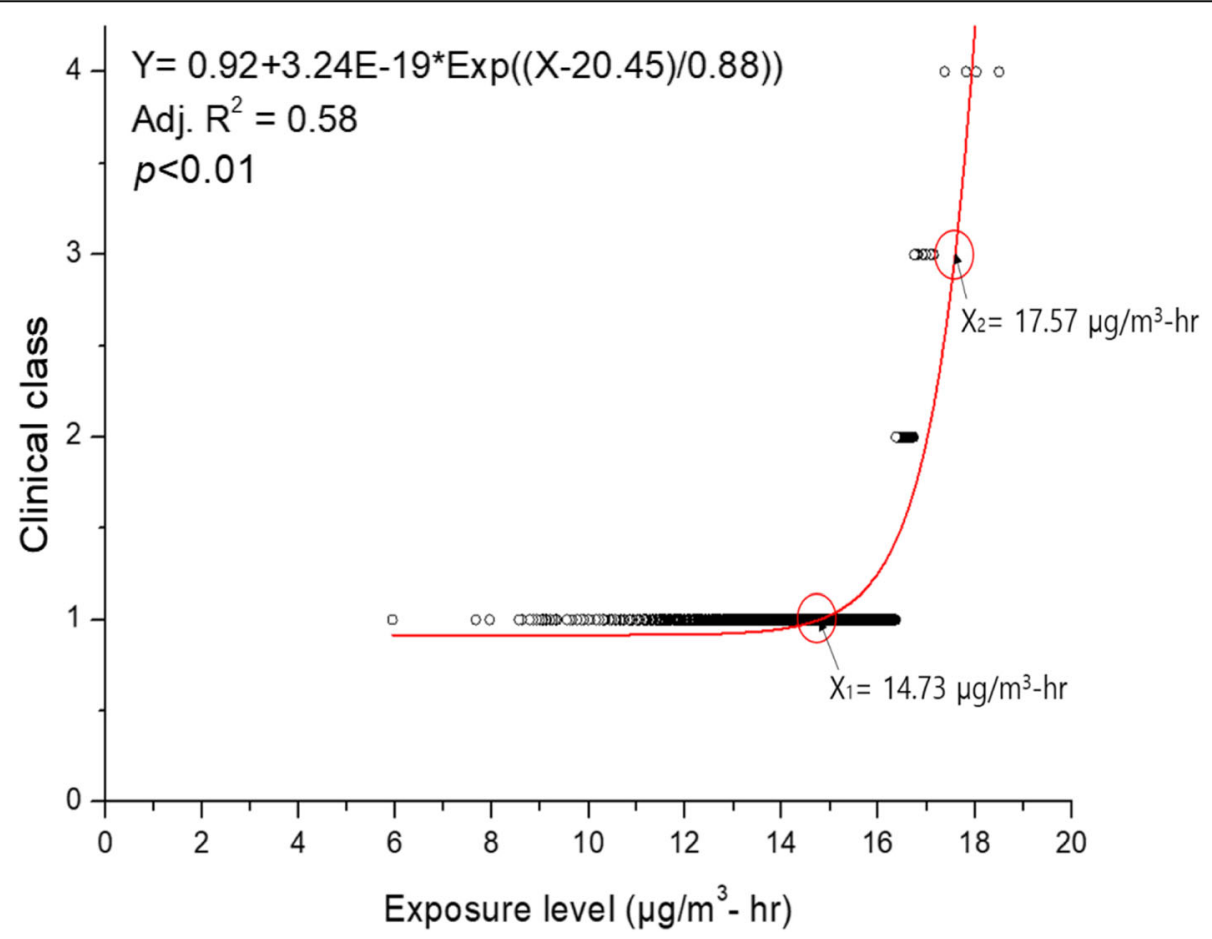

Fig. 3 Regression analysis between exposure level and clinical class 
the indoor concentration and clinical class was about $4.7 \mu \mathrm{g} / \mathrm{m}^{3}$, which was approximately 30 times the difference compared to the derived RfC. This suggests that the exposure-response relationship could be obtained by using a questionnaire compared to RfC induced by animal experiments.

\section{Conclusions}

Since recall bias and various other causes such as recovery of injury and psychological anxiety, exposure assessment to HDs using a questionnaire might not correlate with adverse health effects However, the importance of using questionnaires for past exposure assessments has increased for identifying people who may have been exposed to HDs. To overcome these limitations, the exposure levels were classified according to the clinical class. The overestimation and underestimation groups in the cross-tabulation between exposure ratings and clinical diagnosis classes were analyzed to characterize the causes of misclassification. The overestimation group may have already recovered and responded excessively because of psychological anxiety. However, relatively high mortality rates and surrogate responses observed in the underestimation group, especially under 10 years of age, may have resulted in inaccurate exposure.

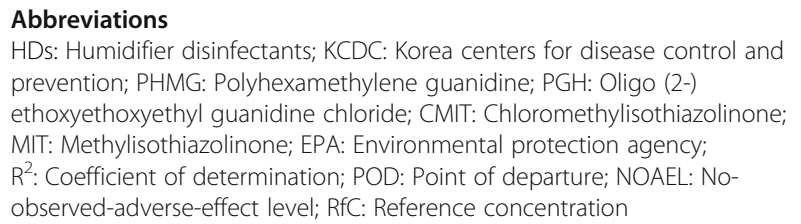

HDs: Humidifier disinfectants; KCDC: Korea centers for disease control and prevention; PHMG: Polyhexamethylene guanidine; PGH: Oligo (2-) ethoxyethoxyethyl guanidine chloride; CMIT: Chloromethylisothiazolinone; MIT: Methylisothiazolinone; EPA: Environmental protection agency; $R^{2}$ : Coefficient of determination; POD: Point of departure; NOAEL: Noobserved-adverse-effect level; RfC: Reference concentration

\section{Supplementary Information}

The online version contains supplementary material available at https://doi. org/10.1186/s12889-021-11459-4.

Additional file 1. Humidifier Disinfectants (HDs) Exposure Survey.

\section{Acknowledgements}

Not applicable

\begin{abstract}
Authors' contributions
$H R$ and JP designed the study and developed the analysis plan and investigation. EK and JY reviewed data analysis results. SL and EJ participated in the research investigation and review and edited the manuscript. $\mathrm{JH}$ and YC2 (Youngtae Choe) participated in the research investigation. WY and YC1 (Yoon-Hyeong Choi) directed its implementation, and reviewed and edited the manuscript. All authors read and approved the final manuscript.
\end{abstract}

\section{Funding}

This work was supported by Korea Environment Industry \& Technology Institute (KEITI) through the Environmental Health Action Program, funded by Korea Ministry of Environment (MOE) (2018001350001).

\section{Availability of data and materials}

The data that support the findings of this study are available from the corresponding author upon reasonable request.

\section{Declarations}

\section{Ethics approval and consent to participate}

This study protocol was approved by the Medical Center Institutional Review Board of Daegu Catholic University (IRB No. CUIRB-2016-011) and was conducted in accordance with the ethical principles for medical research involving human subjects, as defined by the Helsinki Declaration. Study participants provided written informed consent. The consent to participate was obtained from the parents/guardians of the minors (children) included in this study.

\section{Consent for publication \\ Not applicable.}

\section{Competing interests}

The authors declare that they have no competing interests.

\section{Author details}

${ }^{1}$ Department of Occupational Health, Daegu Catholic University, Hayang-eup, Gyeongsan-si, Gyeongbuk 38430, South Korea. ${ }^{2}$ Department of Preventive Medicine, Gachon University College of Medicine, Yeonsu-gu, Incheon 21936, South Korea.

Received: 12 April 2020 Accepted: 7 July 2021

Published online: 27 July 2021

\section{References}

1. Quinn A, Shaman J. Indoor temperature and humidity in New York city apartments during winter. Sci Total Environ. 2017;583:29-35. https://doi. org/10.1016/j.scitotenv.2016.12.183.

2. Daftary AS, Deterding RR. Inhalational lung injury associated with humidifier "white dust.". Pediatrics. 2011;127:509-12.

3. KCDC. Analytical results of the chemical components of various humidifier disinfectant brands from KCDC's parliamentary inspection. Korea: Department of Epidemiology Research, Korea Center for Disease Control and Prevention; 2011.

4. Ryu SH, Park DU, Lee E, Park S, Lee SY, Jung S, et al. Humidifier disinfectant and use characteristics associated with ling injury in Korea. Indoor Air. 2019; 29(5):735-47. https://doi.org/10.1111/ina.12585.

5. Choi Y. Questions and answers about the humidifier disinfectant disaster as of February 2017. Kor J Environ Heal Sci. 2017;43(1):1-22. https://doi.org/10. 5668/JEHS.2017.43.1.1.

6. Kim KW, Ahn K, Yang HJ, Lee S, Park JD, Kim WK, et al. Humidifier disinfectant-associated children's interstitial lung disease. Am J Respir Crit Care Med. 2014;189(1):48-56. https://doi.org/10.1164/rccm.201306-1088OC.

7. Yang HJ, Kim HJ, Yu J, Lee E, Jung YH, Kim HY, et al. Inhalation toxicity of humidifier disinfectants as a risk factor of children's interstitial lung disease in Korea: a case-control study. PLoS One. 2013;8:1-10.

8. KEITI. Statistical data of people enrolled for compensation due to the damaged caused by HDs. https://www.healthrelief.or.kr/home/content/sta ts01/view.do. Accessed 17 Jan 2020.

9. U.S. EPA, Indoor air facts No. 8 use and care of home humidifiers. U.S. Environmental Protection Agency, Office of Air and Radiation, Office of Research and Development, Document Number: 402-F-91-101;1991.

10. Nieuwenhuijsen MJ. Design of exposure questionnaires for epidemiological studies. Occup Environ Med. 2005;62(4):272-80. https://doi.org/10.1136/ oem.2004.015206.

11. Tzilas V, Tzouvelekis A, Chrysikos S, Papiris S, Bouros D. Diagnosis of idiopathic pulmonary fibrosis 'pragmatic challenges in clinical practice'. Front Med. 2017:4:1-7.

12. Paek D, Koh Y, Park DU, Cheong HK, Do KH, Lim CM, et al. Nationwide study of humidifier disinfectant lung injury in South Korea, 1994-2011 incidence and dose-response relationships. Ann Am Thorac Soc. 2015; 12(12):1813-21. https://doi.org/10.1513/AnnalsATS.201504-2210C.

13. Choi YH, Ryu H, Yoon J, Lee S, Kwak JH, Han BY, et al. Demographic characteristics and exposure assessment for applicants who have been injured by humidifier disinfectant-focusing on 4-1 and 4-2 applicants. J Environ Heal Sci. 2018:44:301-14

14. Pietra GG, Capron F, Stewart S, Leone O, Humbert M, Robbins IM, et al. Pathologic assessment of vasculopathies in pulmonary hypertension. J Am Coll Cardiol. 2004:43:25-32. 
15. Kallenberg CGM. The last classification of vasculitis. Clin Rev Allergy Immunol. 2008;35(1-2):5-10. https://doi.org/10.1007/s12016-007-8065-7.

16. Cha YK, Kim JS, Kim Y, Kim YK. Radiologic diagnosis of asbestos in Korea. Korean J Radiol. 2016;17(5):674-83. https://doi.org/10.3348/kj.2016.17.5.674.

17. Das K, Krzywinski M, Altman N. Quantile regression. Nat Methods. 2019;16(6): 451-2. https://doi.org/10.1038/s41592-019-0406-y.

18. Bodiwala D, Luscombe CJ, Liu S, Saxby M, French M, Jones PW, et al. Prostate cancer risk and exposure to ultraviolet radiation: further support for the protective effect of sunlight. Cancer Lett. 2003;192(2):145-9. https://doi. org/10.1016/S0304-3835(02)00710-3

19. Boucher KM, Slattery ML, Berry TD, Quesenberry C, Anderson K. Statistical methods in epidemiology: a comparison of statistical methods to analyze dose-response and trend analysis in epidemiologic studies. J Clin Epidemiol. 1998;51(12):1223-33. https://doi.org/10.1016/50895-4356(98)00129-2.

20. Steenland K, Deddens JA. A practical guide to dose-response analyses and risk assessment in occupational epidemiology. Epidemiology. 2004;15(1):6370. https://doi.org/10.1097/01.ede.0000100287.45004.e7.

21. Paek D, Koh Y, Park DU, Cheong HK, Do KH, Lim CM, et al. Nationwide study of humidifier disinfectant lung injury in South Korea, 1994-2011. Ann Am Thorac Soc. 2015;12(12):1813-21. https://doi.org/10.1513/AnnalsATS.201 504-2210C.

22. Chen Y, Horne SL, Dosman JA. Increased susceptibility to lung dysfunction in female smokers. Am Rev Respir Dis. 1991;143(6):1224-30. https://doi.org/1 0.1164/ajrccm/143.6.1224.

23. Rando TA, Disatnik MH, Yu Y, Franco A. Muscle cells from mdx mice have an increased susceptibility to oxidative stress. Neuromuscul Disord. 1998; 8(1):14-21. https://doi.org/10.1016/50960-8966(97)00124-7.

24. Boezen HM, Vonk JM, van der Zee SC, Gerritsen J, Hoek G, Brunekreef B, et al. Susceptibility to air pollution in elderly males and females. Eur Respir J. 2005;25(6):1018-24. https://doi.org/10.1183/09031936.05.00076104.

25. Thorburn K. Pre-existing disease is associated with a significantly higher risk of death in severe respiratory syncytial virus infection. Arch Dis Child. 2009; 94(2):99-103. https://doi.org/10.1136/adc.2008.139188.

26. Bell ML, Belanger K. Review of research on residential mobility during pregnancy: consequences for assessment of prenatal environmental exposures. J Expo Sci Environ Epidemiol. 2012;22:428-38.

27. Gorman BK, Read JG. Gender disparities in adult health: an examination of three measures of morbidity. J Health Soc Behav. 2006;47(2):95-110. https:// doi.org/10.1177/002214650604700201.

28. Read JG, Gorman BK. Gender and health inequality. Annu Rev Sociol. 2010; 36(1):371-86. https://doi.org/10.1146/annurev.soc.012809.102535.

29. Park K. An analysis of a humidifier disinfectant case from a toxicological perspective. Environ Health Toxicol. 2016;31:1-4.

30. Wing JS, Sanderson LM, Brender JD, Perrotta DM, Beauchamp RA. Acute health effects in a community after a release of hydrofluoric acid. Arch Environ Health. 1991;46(3):155-60. https://doi.org/10.1080/00039896.1991. 9937443.

31. Dayal HH, Brodwick M, Morris R, Baranowski T, Trieff N, Harrison JA, et al. A community-based epidemiologic study of health sequelae of exposure to hydrofluoric acid. Ann Epidemiol. 1992;2(3):213-30. https://doi.org/10.1016/1 047-2797(92)90054-T.

32. Dayal HH, Baranowski T, Li YH, Morris R. Hazardous chemicals: psychological dimensions of the health sequelae of a community exposure in Texas. J Epidemiol Community Health. 1994;48(6):560-8. https://doi.org/10.1136/ jech.48.6.560.

33. Park DU, Friesen MC, Roh HS, Choi YY, Ahn JJ, Lim HK, et al. Estimating retrospective exposure of household humidifier disinfectants. Indoor Air. 2015;25(6):631-40. https://doi.org/10.1111/ina.12180.

34. EPA US. Guidelines for Exposure Assessment. USA: U.S. Environmental Protection Agency; 1992.

35. Paris C, Benichou J, Raffaelli C, Genevois A, Fournier L, Menard G, et al. Factors associated with early-stage pulmonary fibrosis as determined by high-resolution computed tomography among persons occupationally exposed to asbestos. Scand J Work Environ Health. 2004;30(3):206-14. https://doi.org/10.5271/sjweh.781.

36. NIER. A safety study for management of the existing chemicals (I). Seoul. Korea: National Institute of Environmental Research; 2013.

37. U.S. EPA. Risk assessment guidance for superfund volume 1: human health evaluation manual (part F, supplemental guidance for inhalation risk assessment). USA: U.S. Environmental Protection Agency; 2009.

\section{Publisher's Note}

Springer Nature remains neutral with regard to jurisdictional claims in published maps and institutional affiliations.
Ready to submit your research? Choose BMC and benefit from:

- fast, convenient online submission

- thorough peer review by experienced researchers in your field

- rapid publication on acceptance

- support for research data, including large and complex data types

- gold Open Access which fosters wider collaboration and increased citations

- maximum visibility for your research: over $100 \mathrm{M}$ website views per year

At BMC, research is always in progress.

Learn more biomedcentral.com/submissions 